there are besides two or three small annexes, and a court in
the Fine Arts Gallery. The United States of North America are adjacent to Eng. land. Coming very late in the field, a place of honor has nevertheless been reserved to them, and one which will be
well filied despite the shortness of time at the disposition of exhibitors. The United States Agricultural Building is an
extension of that of Great Britain. Belgium and Austria both have very important allotments, and we imagine that importance to those of France and England. Both countries, standing in the first industrial rank, have shown great enter-
prise in taking so large a part in the Exhibition, especially in

Italy has a large area, and though it is too much to expect
that when the exhibits of this country are finally arran that when the exhibits of this country are finally arranged
they will display much of high value in the mechanical arts, they have spared no pains to take a foremost place in other industries. Of Sweden and Norway there is no need to
speak. What they did at Vienna and Philadelphia is a guarantee of their collections now. Spain, too, is largely interested, and China and Japan are now known at exhibitions
as very important contributors. Holland, Portugal, Denmark, South America, all the countries, in short, are here, and all have done their utmost to crown this great triumph
of French energy and power. That is, all but Germany, who, unfortunately for the rest of the world, and we believe for tures, but we may look in vain for the display which was conspicuous at Vienna. Germany's decision was, however, fortunate in some respects for other countries, since had she the expense of others.
By the system of classification adopted, the contents of the
Exhibition are divided into nine groups, subdivided into ninety ch

\section{THE NEW METAL GALLIUM.}

THE metal gallium, which is the latest discovery among
the recognized elements, was first seen by M. Lecoq de Boisbaudran in the autumn of the year 1875, and so named
by him in honor of the land of its discovery, France. Like by him in honor of the land of its discovery, France. Like gallium was discovered by the process of spectrum analysis, ingenuity of M. de Boisbaudran himself, long eminent as a spectroscopist. The spectrum of gallium is characterized by especially brilliant. Hitherto the new metal has been recognized only in certain varieties of zinc blende, that of Pierre-
fitte in the Pyrenees having furnished the chief portion of gallium hitherto obtained from any source whatever-nearBoisbaudran to furnish the dozen grains or so of metal
wherewith he has been able to establish the leading properties of the element. In its appearance gallium manifests a general resemblance to lead, but is not so blue-tinted or quite of being cut with a knife. Like lead again, and unlike zinc,
gallium is not an easily volatile metal. Unlike lead, however, it acquires only a very slight tarnish on exposure to heat. The specific gravity of gallium is a little under 6 , that
of aluminum being $2 \cdot 6$, that of zinc $7 \cdot 1$, and that of lead of aluminum being $2 \cdot 6$, that of zinc $7 \cdot 1$, and that of lead
$11 \cdot 4$. A most remarkable property of gallium is its low melting point. It liquefies completely at $86^{\circ} \mathrm{Fah}$., or below melted at this temperature, it may be cooled down even to
the freezing point of water without solidifying, and may be kept unchanged in the liquid state for months. Indeed, in Academy, it was described as a new liquid metal, similar to mercury; but on touching with a fragment of solid gallium
a portion of the liquid metal in this state of so-called sufa portion of the liquid metal in this state of so-called suf-
fusion it at once solidifies. Unlike lead, again, gallium is a highly crystalline metal, its form being that of a square
octahedron. In its chemical habitudes the rare element gallium shows the greatest analogy to the abundant element
aluminum. In particular it forms a sort of alum not to be distinguished in its appearance from ordinary alum, but containing oxide of gallum instead of oxide of aluminum
alumina. But the chief interest of gallium, from a scientific point of
view, is connected with the history of its discovery. All previously known elements have been discovered, so to any way foreseen, but rather met with as subjects of surprise; but the blende of Pierrefitte was deliber-
ately taken up for examination by M. Lecoq de Boisbaudran in the expectation of finding a new element. The of gallium was, moreover, upon entirely different grounds, jeff, in 1871 , and in a more general way several years earlier by an English chemist, Mr. Newlands. This double pre-
diction was based on a study of the relations of the known atomic numbers of the elements. These numbers have only tion, which, again, is associated in a remarkable manner In the series of numbers, however, certain terms are here and there missing, and in particular a number was missing mediate between those of aluminum and iridium. What tail by M. Mendelejeff in 1871. He predicted, for example, that the specific gravity of the missing metal would prove to
be about 5.9. Operating on very small quantities, M. de Boisbaudran, in the first instance, found the specific gravit
of gallium to be $4 \cdot 7$; but on repeating his determination in 1876 , with special precautions and on a somewhat large though still very small scale, he found it to be exactly 5.935 regard to it.

In a recent number of La Nature, M. G. Tissandier gave the following account of the extraction of a quantity of gal-
lium by $M$. de Boisbaudran, accompanied by a description of lium by M. de Boisbaudran, accompanied by a description of
some of its properties:- Without shrinking from the delicate
and frequently troublesome operations necessary in treating a mass of blende weighing 4,300 kilogrammes, he has suc-
ceeded, in collaboration with M. E. Jungfleisch, in getting out 62 grammes of gallium. "If," say these gentlemen, “" we take account of inevitable losses and of a few grains of gallium remaining in the various products of our operations, we at about one part in sixty thousand, or 16 milligrammes per
kilogramme. The small proportion of matter to extract will at about one part in sixty thousand, or 16 milligrammes per its known composition was calculated at $1 \cdot 64$. The specific
kilogramme. The small proportion of matter to extract will heat of glucina between $0^{\circ}$ and $100^{\circ}$ is 0.2471 . Hence it
sufficiently explain the large amount of time consumed in must be considered analogous to aluminium, its atomic weight
its extraction." must be considered analogous to aluminium,its atomic weight
being $13 \cdot 8$, and its oxide having the formula $\mathrm{Be}_{2} \mathrm{O}_{3}$.

JAPANESE ISINGLASS.

By HARRY NAPIER DRAPER.

\begin{tabular}{l|l} 
THIs product was given to me some time since by Dr. \\
Anilogrammes of blende were concentrated in a mass weigh-
\end{tabular} ing about 100 kilos., containing the whole of the gallium. Aquilla Smith, who had procured it in the London Docks.
From Javel this mass of concentrated stuff was transported It is in the form of flattened, somewhat contorted, and to the laboratory of M. Lecon de Boisbaudran at Cognac, always curved threads, the longest of which does not exceed a metallic condition at the Ecole de Pharmacie, at Paris. After a long succession of attacks by acids and alternative
precipitations, the metals associated with gallium, such as zinc, iron, cadmium, iridium, \&c., were eliminated. The
gallium in the residue of the solutions from which the other it we at once decided by burning one of the threads, when
it be found that no odor of charred animal matter is metals had been residue of the solutions from which the other "by the action of the electric current. "The deposition of metallic gallium," say Messrs. Lecoq
de Boisbaudran and Jungfleisch, "is only carried out sucessfully under certain special conditions. The intensity of
he electric current, for instance, should vary with the state f electric current, for instance, should vary with the state
hould always, but the surface of the negative electrode fallium in twenty-four hours, forty Bunsen cells (18 cenimeters high), ranged in eight parallel rows, each of five cells in tension, acted on a negative electrode, the double the positive electrode had a development of about 450 square quently forms lon metal on being thrown down cold freappearance of needics, fixed normally to the electrode by
one of their extremities; some few have reached the length of 3 centimeters. Above $30^{\circ}$ the metal runs in drops, which coalesce at the foot of the electrode." Crystals of gallium
were presented on behalf of the operators to the Academy of Sciences by M. Berthelot, in its sitting of February 18th.
These crystals, which have a distinct grayish-blue metallic These crystals, which have a distinct grayish-blue metallic
luster, belong distinctly to the octahedric system, but their langles have not yet been measured, their faces being slightly
a.rounded. They are mounted on small glass stems, and kept under a glass globe from the contact of the air.
Crystallization was effected by introducing

Crystallization was effected by introducing a platinum
ire carrying a particle of solid gallium into the metal cooled $10^{\circ}$ or $15^{\circ} \mathrm{C}$. below its melting point. After the lapse of
very short period, varying from 3 to 10 a ric crystals show themselves, very slightly modified at their the accompanying drawings of the full natural size. If the crystals are not promptly withdrawn as soon as formed, the and the base enlarges.

Gallium is a hard and malleable metal; it takes under the hammer the polish of the anvil, but rapidly grows harder and brittle, and is then liable to fly to pieces. In spite of its uster in the atmosphere of a laboratory constantly loaded ith acid vapors, and undergoes no alteration in appearance
boiled water. In aerated water it tarnishes slightly. Gallium, which melts at $30^{\circ}$, may be kept superfused in a
ube hermetically sealed. MM. Boisbaudran and Jungfleisch have prepared a certain quantity of it in this condition. It re have prepared a certain quantity of it in this condition. It redition, gallium has the brilliant whiteness of tin or silver. it would be of great value for the determination of tempera ures rising to $300^{\circ}$ or $400^{\circ} \mathrm{C}$., but its habit of clinging to the
sides of the glass vessel in which it may be contained con-
titutes at present an impediment in the way of its being stitutes at present an impediment in the way of its being
used for thermometric purposes. It is possible that some used for thermometric purposes. It is possible that some
means may be found for correcting this tendency, and that pe new metal may thus be made capable of receiving variou
pplications in the domain of experimental science. Gallium leaf has also been prepared by running the melted
metal between heated glass surfaces. On cooling, especially f the cooling is carried out under water, the metal is casily etached from the glass. This specimen melts in the hand
t retains its characteristic dull blue metallic reflection. A small bar has also been cast, the elasticity and malleability
of which are easily demonstrable. Crystallized gallium prepared cold by electrolysis of a poand gives rise to bubbles of gas. "By electrolysis of a liquor btained, especially toward the end of the operation, a puffy metallic mass swelling in warm water; and having the aspect
of an ammonium amalgam. Kneaded in water at $40^{\circ} \mathrm{C}$., his mass contracts and is finally resolved into ordinary fluid Some new compounds of gallium, comprising the chloride bromide, and anhydric iodide, have been presented to the
Academy. Chlorine attacks gallium in the cold state very actively, with an abundant disengagement of heat. The proless if pure. It is well crystallized, very fusible, easily beatmosphere. The action of bromine is less energetic than
thos of
To get the iodide it must be slightly that of "

\section{GLUCINIUM.}

By L. F. Nilson and O. Pettersson.

GLOCINIUM in its salts presents certain analogies both with the magnesium and with the aluminium group, but no deci-
sive clew is afforded to the true atomicity of the metal, which can only be deduced from its specific heat. The preparation
of the metal is difficult; the authors could not succeed in of the metal is difficult; the authors could not succeed in they adopted, therefore, the process of Wöhler and Debray, wrought-iron crucible closed with a screw. Glucinium thus
obtained is a steel or tin-gray metal, of the sp. gr. 1.901 at $0^{\circ}$. It is hard and crystallizes readily. If melted it breaks salt is readily volatilized. It is inalterable in the air, and phur does not affect it. Before the oxidizing flame it be-
comes covered with a layer of oxide, but does not take fire. comes covered with a layer of oxide, but does not take fire.
It has no action upon water either warm or cold. It decom-
poses hydrochloric and hydrosulphuric acid and the alkaline poses hydrochloric and hydrosulphuric acid and the alkaline
hydrates, hydrogen being evolved very briskly if heat is aphydrates, hydrogen being evolved very briskly if heat is ap
plied. Nitric acid attacks it more slowly. The sp. gr. of plied. Nitric acid attacks it more slowly. The sp. gr. of its known composition was calculated at $1 \cdot 64$ The specific
teat of
glucina between $0^{\circ}$ and $100^{\circ}$ is 0.2471 . Hence it evolved. Shortly summed up, the properties of this body
are as follows:- It is turned blue by iodine, and is insoluble in alcohol, water even after many hours' boiling, dilute potash solution, acids, ammonia, and ammoniacal copper sul-
phate. My friend, Dr. Richardson has been kind enough to make for me two sections of this substance. These examined by the microscope show a ruptured cellular structforward this note in order that those whose attention may be called to it, and who may have met with this or other
allied substances, may be induced to communicate any information of which they may be possessed. I should myself have pronounced it to be the Gelose of Payen, a body
extracted from Gelidium Cornelum and other Algg, were it ing water, and as yielding a translucent jelly, while the sodescriptions of Payen's Gelose which I have seen is it men-
tioned that it is colored by iodine. At the time, now nearly a year since, when Dr. Smith gave me this specimen, I made uses, but without the slightest success.
Although not true isinglass, it seemed possible that the article under examination might be some other product of
the animal kingdom. This would involve the question being applicable to all such cases, I may be excused for books of analysis. This test is best applied as follows:-
You cut from a clean lump of sodium a few parings with a You cut from a clean lump of sodium a few parings with a
knife, and intimately mix them on the bottom of a small porcelain crucible, with the suspected substance in as minute
a state of division as possible. Then the mixture is ignited. When it has become cool it is heated with water, filtered,
and a mixed solution of a per and proto-salt of iron added, and a mixed solution of a per and proto-salt of iron added,
and afterward hydrochloric acid. Russian isinglass thus Since this paper was read Mr. Grindley has pointed out
Sited gives a copious precipitate of Prussian blue. glycerine, and gives a
colored blue by iodine.

GALLIUM.

By M. Berthelot.

M. LECOQ DE BoIsBADDRAN having placed at the arthor's disposal an ingot of gallium weighing 34 grms., he deterand also its melting heat, making use of his ordinary methbut it may be kept liquid in a state of superfusion down to twice, one experiment between $119^{\circ}$ and $13^{\circ}$, and the other between $106^{\circ}$ and $12 \cdot 5^{\circ}$; the value found was 0.0802 . The This determination must not be made too near the point 0 . crystals into superfused gallium, when the metal crystallizes
rapidly. At $13^{\circ}$ the author obtained the mean result $+19 \cdot 11$ rapidly. At $13^{\circ}$ the author obtained the mean result $+19 \cdot 11$
cals. This number remains sensibly unchanged at all temperatures between $30^{\circ}$ and $0^{\circ}$. If referred to the atomic
weight, $69 \cdot 9$, it becomes 1.33 cals. The atomic specific weight, 69.9 , it becomes 1.33 cals. The atomic specific
heat in the liquid state $=5.59$, and in the solid 5.52 . This
is the same as that of aluminium $(5 \cdot 53)$ and glucinium $(5 \cdot 64)$.

ACTION OF OXYGEN UPON THE ACID CHLO RCTION OF OXYGEN UPON THE ACID CHLO-
IUM. By M. Berthelot.

THE displacement ofchlorine by oxygen with the formation
of alumina should disengage a heat about $+34 \cdot 9$ placement of gaseous iodine in the same manner liberates $+109 \cdot 5^{\circ}$, an enormous value, which explains the ignition
of aluminium iodide. The same holds good with the iodides of aluminium iodide. The same holds good with the iodides are all combustible. The displacement of gaseous bromine dry oxygen liberates $+62 \cdot 2$

\section{A NEW WAY OF SEPARATING ARSENIC FROM}

By Mm. de Clermont and Frommel.

SUPPOSING a mixture of arsenic, antimony, and tin, the

whole is converted into sulphides by treatment with sulphu-
reted hydrogen, after having acidulated with hydrochloric acid, adding also tartaric acid if antimony is present. When the mixture is saturated it is allowed to stand in a warm
place till the odor of sulphureted hydrogen is no longer perceptible, and is then thrown upon a filter and washed with
much care, as the least residue of hydrochloric acid would much care, as the least residue of hydrochloric acid would is then transferred into a flask full of water, and heated to a boil. The reaction is more rapid in a retort through which
a current of air is passed. If the quantity of arsenic does water suffices for the complete dissociation of the sulphides.
The residue is then filtered, and the entire quantity of the arsenious acid is fo
ordinary methods.

DIBRomide of ACETIC ACID.-C. HELL and O. MÜHLone another in the slightest when brought together, the addition of a minute quantity of $\mathrm{CS}_{2}$ causes at once a development of heat, and the mixture is changed rapidly into mass of crystals of the compostion $\mathrm{C}_{2} \mathrm{H}_{4} \mathrm{O}_{2}$. $\mathrm{Br}_{2}$. They
form at first orange-colored tufts of needles, but change on standing into red thick prisms. The compound melts at
$36^{\circ}$, is excessively hygroscopic, attacks the eyes, sublimed. Water decomposes it. Other liquids, such as $\mathrm{CCL}_{4}$ or $\mathrm{CHCl}_{3}$, do not possess this peculiar catalytic action
of $\mathrm{CS}_{2}$, which only can cause the formation of this new of $\mathrm{CS}_{2}$, which only can compound.
molecular con This point may be decided by a qualitative test, which, Since this paper was read Mr. Grindley has pointed out
that this so-called Japanese isinglass dissolves readily in
glycerine, and gives a clear and firm jelly. This jelly is fusion. The melting heat is determined by introducing som not exceed 2 decigrms. the distillation of 500 to 600 c.c. of 